\title{
Shift of the TSH reference range with improved iodine supply in Northeast Germany
}

\author{
Till Ittermann ${ }^{1}$, Rehman M Khattak', Matthias Nauck ${ }^{2}$, Caio M M Cordova ${ }^{4}$ and \\ Henry Völzke ${ }^{1,3}$ \\ ${ }^{1}$ Institute for Community Medicine, Ernst Moritz Arndt University, University of Greifswald, Walther-Rathenau \\ Straße 48, D-17475 Greifswald, Germany, ${ }^{2}$ Institute of Clinical Chemistry and Laboratory Medicine, University of \\ Greifswald, Greifswald, Germany, ${ }^{3}$ DZHK (German Center for Cardiovascular Research), Partner Site Greifswald, \\ University of Greifswald, Greifswald, Germany and ${ }^{4}$ Departamento de Ciências Farmacêuticas, Universidade \\ Regional de Blumenau, Blumenau, Brazil
}

\author{
Correspondence \\ should be addressed \\ to T Ittermann \\ Email \\ till.ittermann@ \\ uni-greifswald.de
}

\begin{abstract}
Objective: Germany was iodine deficient until the mid-1990s when a nationwide iodine fortification program became effective. It is expected that after a longer period of sufficient iodine supply, median TSH values in the general population will shift to the right. Hence, the previous TSH reference range does not reflect the current TSH distribution in the general population of Germany. Thus, we aimed to establish a new reference range for serum TSH levels.

Design and methods: We used data from the Study of Health in Pomerania TREND, a population-based study including 4420 individuals. The reference population consisted of 1596 individuals without diagnosed thyroid diseases or thyroid-related findings in ultrasound and serum analysis. Serum TSH levels were measured by an immunochemiluminescent procedure on a Siemens Dimension Vista.

Results: The overall reference range for TSH was $0.49 \mathrm{mIU} / \mathrm{l}(95 \% \mathrm{Cl}=0.44 ; 0.53)-3.29 \mathrm{mIU} / \mathrm{l}(95 \% \mathrm{Cl}=3.08$; 3.50$)$. The lower reference limit differed significantly by sex, whereas the upper reference limit showed no significant difference between males and females. Age was significantly associated with the 2.5th TSH percentile in males but not in females, whereas age was significantly associated in males and females for the 97.5th TSH percentile.

Conclusions: We demonstrate a shift toward the right of the TSH reference range in comparison with data from the same study region 10 years earlier, which is likely due to the improved iodine supply of the study region. Our study indicates that TSH reference limits are dependent on past and current iodine supply of populations.
\end{abstract}

\section{Introduction}

There is an ongoing debate on which reference range for serum thyroid-stimulating hormone (TSH) levels is appropriate, particularly to define hypothyroidism $(1,2,3,4,5)$. That debate is related to the heterogeneity in TSH reference ranges established in previous studies $(6,7,8$, $9,10,11,12,13)$ with differences of the upper TSH limit between $2.12 \mathrm{mIU} / 1$ (12) and $5.30 \mathrm{mIU} / 1$ (13). These discrepancies can be explained by different study populations, age ranges (4), laboratory methods (14), and iodine supplies of populations $(15,16)$. In regions with iodine deficiency, reference intervals for serum TSH levels tend to be lower than that in regions with sufficient iodine supply, leading to higher reference intervals in North America (6) and East Asia $(8,10,13)$ than that in large parts of Europe $(7,9,12)$, where most countries are inherently iodine deficient (17).

Besides the current supply, the history of iodine supply also influences regional TSH reference ranges. In Germany iodine deficiency persisted until the mid 1990s. In 1993 an improved legislation was established, followed by an increased use of iodized salt in households and food industries. Consequently, median iodine

Published by Bioscientifica Ltd. 
excretion levels increased in German children (18) and adults (19), and, in parallel, a decrease in goiter prevalence in school children was detected during that period (20).

Also paralleled by increased iodine supply in Germany, the distribution of TSH values initially shifted toward the left during the first years after the iodine fortification program became effective, which was demonstrated by the Study of Health in Pomerania (SHIP-0). SHIP-0 randomly recruited participants for baseline examinations in the first years (1997-2001) after improved iodine supply of the Northeast German population (21). During that time, the TSH reference range was relatively low (0.25-2.12 mIU/l) (12). In SHIP-0 (12), individuals with diagnosed thyroid disorders and also individuals with previously undetected thyroid diseases based on ultrasound and serum analyses were excluded to define the reference population. However, inclusion of individuals with small autonomous areas not detectable by thyroid ultrasound into the reference population might have favored the left shift of the resulting TSH range (22).

After the persistence of improved iodine supply for several years, it can be expected that the TSH distribution in the general population shifts toward the right, which has already been observed in Germany $(23,24)$. Thus, the TSH reference interval established during the transition phase between iodine deficiency and sufficiency may not reflect the current distribution of TSH values in the general population of Germany, which might result in unnecessary clinical work-up and high costs for the German health care system. Indeed, the prescription rate of levothyroxine increased by 55\% between 2004 and 2012 in Germany (25).

Against this background, an update of the TSH reference range is urgently needed. We used data from a new population-based study conducted between 2008 and 2012 in Northeast Germany to establish current TSH reference ranges.

\section{Subjects and methods}

\section{Study population}

SHIP TREND-0 is a population-based study conducted in the rural Northeast of Germany between 2008 and 2012 (21), the same study region as for SHIP-0 (examined between 1997 and 2001). For SHIP-TREND-0, a random, age- and sex-stratified sample of 8826 eligible subjects were drawn from the population registry, of which 4420 subjects participated (net response 50.1\%). All participants gave informed written consent. SHIP-TREND-0 followed the recommendations of the Declaration of Helsinki and was approved by the Ethics Committee of the University of Greifswald. From the study population, we excluded 25 individuals with missing TSH values.

\section{Thyroid assessments}

Blood samples were taken between 0700 and $1300 \mathrm{~h}$ and analyzed in the central laboratory of the University Medicine Greifswald. The participants without known diabetes were asked to fast over at least $8 \mathrm{~h}$ before the examination. The median fasting time before blood sampling was $10.7 \mathrm{~h}$ (25th percentile $2.5 \mathrm{~h}$; 75 th percentile $12.9 \mathrm{~h}$ ). Serum TSH levels were measured by an immunochemiluminescent procedure (Dimension Vista, Siemens, Eschborn, Germany). The analytical sensitivity of the TSH assay was $0.005 \mathrm{mIU} / \mathrm{l}$; the TSH working range was $0.005-100 \mathrm{mIU} / \mathrm{l}$. The (low or high) inter-assay coefficients of variations were $2.04 \%$ or $2.20 \%$ for TSH. A method of comparison revealed slightly higher TSH levels with the SHIP-0 than that with the SHIP-TREND laboratory method (Fig. 1). Serum autoantibodies to thyroperoxidase (TPOAb) were measured by an enzyme immunoassay (VARELISA, Elias Medizintechnik GmbH, Freiburg, Germany). The detection limit of this assay was $1 \mathrm{IU} / \mathrm{ml}$. Serum anti TPOAb exceeding a level of $200 \mathrm{IU} / \mathrm{ml}$ were considered positive. Urinary iodide concentrations were measured from spot urine samples. Iodine concentrations were evaluated by photometric procedure (Photometer ECOM 6122, Eppendorf, Hamburg, Germany) with the Sandell and Kolthoff reaction (26).

Thyroid ultrasonography was performed with a portable device using a 13-MHz linear array transducer (Vivid-I, General Electrics, Frankfurt, Germany). Thyroid volume was calculated as length $\times$ width $\times$ depth $\times$ $0.479(\mathrm{ml})$ for each lobe. Goiter was defined as a thyroid volume exceeding $18 \mathrm{ml}$ in women and $25 \mathrm{ml}$ in men (27). The normal thyroid echo pattern was classified as homogeneous. An homogeneous echo pattern with reduced echogenicity was defined as hypoechogenic. If the echo pattern was not homogeneous, showing small lesions or distinct diffuse abnormalities in the echotexture of the gland, it was classified as inhomogeneous. Nodular changes exceeding $2 \mathrm{~mm}$ in diameter were defined as nodules.

History of diagnosed thyroid diseases was inquired by computer-assisted personal interviews. All participants were asked to bring their medications to the examination center. Intake of thyroid medication was defined by the anatomic-therapeutical-chemical (ATC) code H03. 


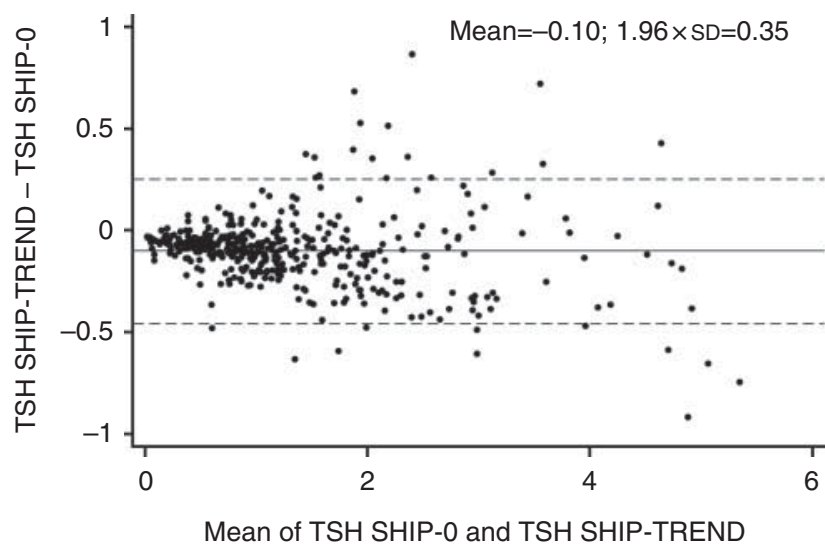

Figure 1

Bland-Altman plot to compare laboratory methods of TSH between SHIP-0 and SHIP-TREND.

\section{Definition of the reference population}

To define the healthy reference population, we excluded all individuals with at least one of the following conditions: previous diagnosed thyroid disease $(n=830)$, intake of thyroid medication $(n=465)$, positive TPO antibodies $(n=194)$, goiter $(n=1383)$, at least one thyroid nodule $(n=1534)$, hypoechogenic $(n=285)$, or inhomogeneous thyroid pattern $(n=1084)$. This established a reference population of 1596 individuals (617 women).

\section{Statistical analyses}

As recommended by the Clinical and Laboratory Standards Institute, we used a nonparametric method to establish reference intervals for TSH (28). We used quantile regression to directly model percentiles of TSH in dependence of age and sex (29). Reference intervals were defined according to the 2.5 th and 97.5 th percentile of TSH. To account for possible nonlinear associations between age and the respective percentile of TSH, we applied multivariable fractional polynomials (30). This method tests transformations of age by comparing the fit of quantile regression models with and without transformations of the exposure variables. If the fit of the model with the transformed exposure variable was superior to the fit of the model without exposure transformation, the exposure variable was used transformed in the quantile regression model. A $P<0.05$ was considered as statistically significant. All analyses were performed with Stata 13.1 (Stata Corporation, College Station, TX, USA).

\section{Results}

\section{Description of the study population}

Median age was similar between SHIP-0 (51 years) and SHIP-TREND (53 years). The proportions of males were $49.1 \%$ in SHIP-0 and $48.5 \%$ in SHIP-TREND. The median BMI was lower in SHIP-0 $\left(26.9 \mathrm{~kg} / \mathrm{m}^{2}\right)$ than in SHIP-TREND $\left(27.5 \mathrm{~kg} / \mathrm{m}^{2}\right)$, and the frequency of current smokers was $30.3 \%$ in SHIP-0 and $26.9 \%$ in SHIP-TREND.

In the whole population of SHIP-TREND-0, the median iodine excretion level was $114 \mu \mathrm{g} / \mathrm{l}$. The median serum TSH level was $1.17 \mathrm{mIU} / 1$ (25th percentile 0.79; 75th percentile 1.67 ) with a slightly higher median in women $(1.20 \mathrm{mIU} / \mathrm{l})$ than in men $(1.13 \mathrm{mIU} / \mathrm{l})$. Individuals with a previously diagnosed thyroid disease had a lower median serum TSH level than individuals without known thyroid disease $(1.07 \mathrm{mIU} / \mathrm{l}$ vs $1.18 \mathrm{mIU} / \mathrm{l})$. Median serum TSH levels were lower in individuals with thyroid medication intake than in those without (1.08 mIU/l vs $1.17 \mathrm{mIU} / \mathrm{l})$.

After excluding individuals with diagnosed thyroid disease or thyroid medication intake, we detected differences in serum TSH levels among individuals with and without not yet diagnosed thyroid diseases (Fig. 2). Serum TSH levels were higher in individuals with positive TPO antibodies or with a hypoechogenic thyroid pattern, while serum TSH levels were lower in individuals with goiter or thyroid nodules. Only small differences in TSH values were present between individuals with and without an inhomogeneous thyroid pattern.

In the reference population, fasting participants $(\geq 6 \mathrm{~h}$; median $=1.37 \mathrm{mIU} / \mathrm{l})$ had slightly higher $\mathrm{TSH}$
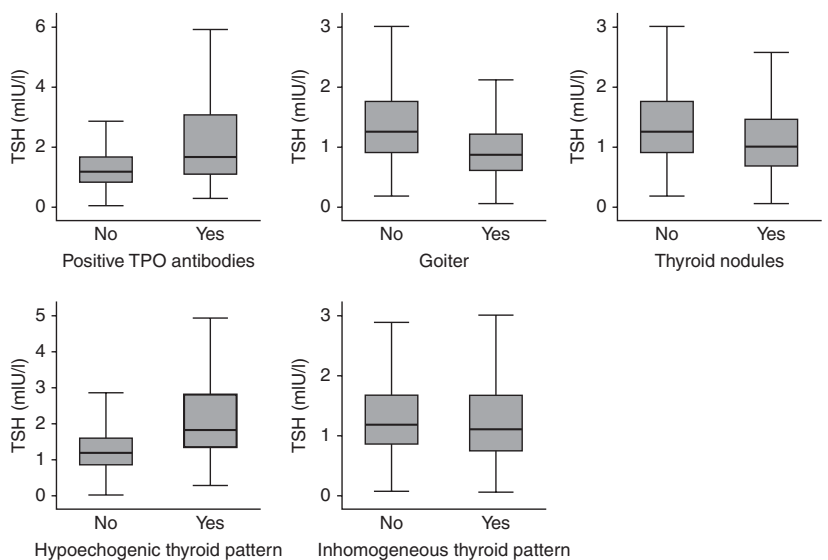

Figure 2

Box plots for serum TSH levels stratified by nondiagnosed thyroid diseases. 
Table 1 Formulas for calculation of age- and sex-specific reference intervals for the thyroid-stimulating hormone.

\begin{tabular}{|c|c|c|}
\hline & 2.5th percentile & 97.5th percentile \\
\hline Males & $0.7254-0.0054 \times$ age & $2.6541+700.6696 \times 1$ age $^{2}$ \\
\hline Females & $0.7347-0.0036 \times$ age & $4.3502-0.0259 \times$ age \\
\hline
\end{tabular}

values than participants who were nonfasting $(<6 \mathrm{~h}$; median $=1.25 \mathrm{mIU} / \mathrm{l}$ ), but that difference was not statistically significant after adjustment for age and sex $(P=0.287)$. Time of blood sampling had a significant impact on median TSH values in the reference population even after adjustment for age and sex with a median decrease in serum TSH levels by $0.06 \mathrm{mIU} / 1$ (95\% CI =0.03; 0.10) per hour between 0700 and $1300 \mathrm{~h}$.

\section{Reference intervals}

The overall reference range for serum TSH levels was $0.49 \mathrm{mIU} / 1(95 \% \mathrm{CI}=0.44 ; 0.53)-3.29 \mathrm{mIU} / 1 \quad(95 \% \mathrm{CI}=$ $3.08 ; 3.50)$. The lower reference limit differed significantly by sex $(0.46 \mathrm{mIU} / 1$ in males and $0.57 \mathrm{mIU} / 1$ in females; $P=0.028$ ), whereas the upper reference limit showed no significant difference between males and females (3.18 mIU/1 in males and 3.46 in females; $P=0.194$ ).

The TSH reference limits decreased with age. Age was significantly associated with the 2.5 th TSH percentile in males $(\beta=-0.005 ; 95 \% \mathrm{CI}=-0.008 ;-0.002 ; P<0.001)$ but not in females $(\beta=-0.004 ; 95 \% \mathrm{CI}=-0.009 ; 0.002$; $P=0.213$ ). Age was significantly associated with the 97.5 th TSH percentile in males and females. In males, age was nonlinearly associated with the 97.5th TSH percentile $\left(\beta\right.$ for $1 /$ age $^{2}=700.67 ; 95 \% \quad C I=116.10 ; 1285.24$; $P=0.019)$, while in females age was linearly associated with the 97.5 th $\mathrm{TSH}$ percentile $(\beta=-0.026 ; 95 \%$ $\mathrm{CI}=-0.046 ;-0.006 ; P=0.012)$. Age-related reference curves for serum TSH levels stratified by sex are shown in Fig. 3 and formulas for calculation of age- and sex-specific reference intervals are given in Table 1 . Time of blood sampling was not significantly associated with the 2.5 th and 97.5th TSH percentile.

\section{Discussion}

We established a new TSH reference range for Northeast Germany using recent data. In comparison with data from our study region 10 years earlier (12), there is a $96 \%$ shift of the lower reference limit from $0.25 \mathrm{mIU} / 1$ to $0.49 \mathrm{mIU} / 1$ and a 55\% shift of the upper reference limit from $2.12 \mathrm{mIU} / 1$ to $3.29 \mathrm{mIU} / 1$.

This shift cannot be explained by different populations, because both reference ranges were established on population-based samples covering an age range of 20-80 years of the same general population. Distributions of age, sex, and current smoking were quite similar between SHIP-0 and SHIP-TREND, but the median BMI was slightly higher in SHIP-TREND than in SHIP-0. This slight increase in median BMI may have contributed to the higher TSH reference limits in SHIP-TREND than in SHIP-0, because previous studies showed positive associations between serum TSH levels and BMI $(31,32,33)$. However, the detected differences in median BMI might be too small to explain the magnitude of the shift of the TSH reference range.

Laboratory methods applied to SHIP-0 and SHIPTREND were similar. In both studies, serum TSH levels were measured in the same laboratory. Even though different laboratory methods were used, a method comparison showed only small differences across the two methods in 400 serum samples, with slightly higher TSH levels in the SHIP-0 laboratory method. For the thyroid ultrasound measurements, which were the basis for exclusion criteria in both studies, transducers with different resolutions were used $(5 \mathrm{MHz}$ in SHIP-O and $13 \mathrm{MHz}$ in SHIP-TREND). While the different transducers had no impact on the comparability of the thyroid volume between SHIP-0 and SHIP-TREND, a considerably higher frequency of individuals with thyroid nodules were detected in SHIP-TREND than in SHIP-0 due to the higher resolution of the transducer. Thus, in SHIP-TREND, more individuals with thyroid nodules were excluded for

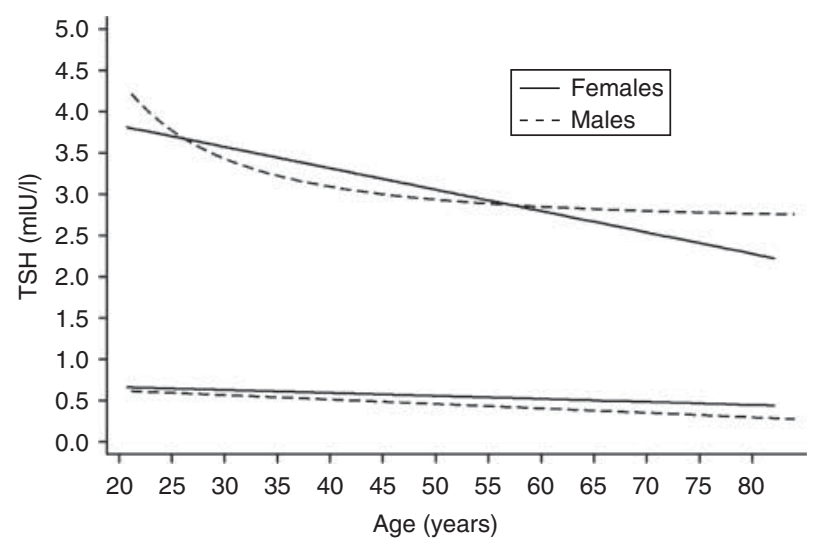

Figure 3

Age-related reference curves for serum TSH levels stratified by sex. 
definition of the reference population than in SHIP-0, which might have led to higher serum TSH reference intervals in SHIP-TREND than in SHIP-0 due to the more sensitive characterization of thyroid nodules in SHIP-TREND than in SHIP-0. However, as most individuals with thyroid nodules have enlarged thyroid glands at the same time and thus have been also excluded from the SHIP-0 reference population, the frequencies of excluded subjects for definition of the reference population was similar between SHIP-0 (65.5\%) and SHIP-TREND (63.7\%).

It is likely that the change in the TSH reference range between SHIP-0 and SHIP-TREND is mainly related to the improved iodine supply. This dependency of the TSH reference range on the iodine supply has also been previously reported in a Danish population (15). Thus, the emphasis should not be the definition of one upper reference limit for serum TSH levels, but the definition of an accurate upper reference limit depending on the current iodine supply of the region under study. This has also been outlined in the recent guidelines of the American Thyroid Association (2).

Of very important note, apart from the definition of an accurate and current $\mathrm{TSH}$ reference range within a population, it has to be pointed out that the resulting reference limits have only diagnostic significance, which implies that values outside a region-specific reference range may indicate a thyroid disorder but do not necessarily mean that a thyroid disease is present or that values outside a reference range forecast worse outcome risks (34). For the latter, reference intervals of prognostic significance or therapeutical cut-offs are needed which can only be assessed from longitudinal rather than from a cross-sectional studies. We assume that the increasing prescription of thyroxin in the population of Germany might be at least partly explained by an incorrect use of the TSH reference range as the basis for therapeutic decisions in clinical practice.

In Germany, iodisation of table salt and cattle food is based on the voluntary principle. Thus, there might be differences in iodine supply across the regions of Germany (23). However, our new established reference range for serum TSH levels showed good agreement with recent reference ranges established in East (7) and South Germany (35). These findings mirror the improved iodine supply in the whole of Germany.

Two studies from the USA demonstrated an increase in serum TSH reference limits $(4,36)$ with increasing age, whereas in our study serum TSH reference limits decreased with age. The reasons for these discrepant findings might be twofold. First, the different history of iodine supply might play an important role. Germany is a country with historical iodine deficiency and a high prevalence of hyperthyroidism, thyroid nodules, and goiter (37), while the iodine supply was adequate with a tendency toward an oversupply in the USA over the last 60 years (17). Thus, TSH levels of the elderly in Germany tend to be lower than those of the younger age groups. The difference in serum TSH levels between the young and the elderly in Germany might be furthermore fostered by the improved iodine supply over the last 15 years. In the USA, however, the elderly tend to increase their serum TSH levels with age possibly because of the tendency toward iodine oversupply. A second reason for the discrepant findings between our study and the studies from the USA $(4,36)$ might be related to the applied exclusion criteria. The US studies did not exclude individuals with thyroid sonography findings, while in our study, participants with sonographic thyroid abnormalities were excluded. Particularly, individuals with a hypoechogenic or an inhomogeneous thyroid pattern might have affected the TSH reference ranges established in the US studies $(4,36)$, because such thyroid patterns are indicative of autoimmune thyroid diseases $(38,39)$. Indeed, in our population we see that participants with a hypoechogenic thyroid pattern have higher serum TSH levels than participants without such a pattern. However, serum TSH levels did not differ by participants with and without an inhomogeneous thyroid pattern in our study, but this difference might be more pronounced in populations with iodine oversupply, because in regions of (previous) iodine deficiency an inhomogeneous thyroid pattern may more commonly mark early nodular changes.

A circadian trend of individual TSH levels over the day with highest levels in morning has been reported (40). In our study blood samples were taken between 0700 and $1300 \mathrm{~h}$, but the time of blood sampling had no significant impact on the reference limits. Likewise, fasting time did not significantly influence the TSH reference limits.

In conclusion, we demonstrate a shift toward the right of the TSH reference range in comparison with data from the same study region 10 years earlier, which is likely due to the improved iodine supply of the study region. Our study indicates that TSH reference limits are dependent on past and current iodine supply of populations.

Declaration of interest

The authors declare that there is no conflict of interest that could be perceived as prejudicing the impartiality of the research reported. 


\section{Funding}

The Study of Health in Pomerania is part of the Community Medicine Research Network of the University Medicine Greifswald, which is funded by the State Mecklenburg-West Pomerania and the University Medicine Greifswald. Analyses were further supported by the German Research Foundation (DFG VO955/10-2) and the BMELV (07HS003).

\section{References}

1 Brabant G, Beck-Peccoz P, Jarzab B, Laurberg P, Orgiazzi J, Szabolcs I, Weetman AP \& Wiersinga WM. Is there a need to redefine the upper normal limit of TSH? European Journal of Endocrinology $2006 \mathbf{1 5 4}$ 633-637. (doi:10.1530/eje.1.02136)

2 Garber JR, Cobin RH, Gharib H, Hennessey JV, Klein I, Mechanick JI, Pessah-Pollack R, Singer PA \& Woeber KA. Clinical practice guidelines for hypothyroidism in adults: cosponsored by the American Association of Clinical Endocrinologists and the American Thyroid Association. Thyroid 201222 1200-1235. (doi:10.1089/thy.2012.0205)

3 Laurberg P, Andersen S, Carle A, Karmisholt J, Knudsen N \& Pedersen IB. The TSH upper reference limit: where are we at? Nature Reviews. Endocrinology 20117 232-239. (doi:10.1038/nrendo.2011.13)

4 Surks MI \& Boucai L. Age- and race-based serum thyrotropin reference limits. Journal of Clinical Endocrinology and Metabolism 2010 95 496-502. (doi:10.1210/jc.2009-1845)

5 Wartofsky L \& Dickey RA. The evidence for a narrower thyrotropin reference range is compelling. Journal of Clinical Endocrinology and Metabolism 200590 5483-5488. (doi:10.1210/jc.2005-0455)

6 Hollowell JG, Staehling NW, Flanders WD, Hannon WH, Gunter EW, Spencer CA \& Braverman LE. Serum TSH, T(4), and thyroid antibodies in the United States population (1988 to 1994): National Health and Nutrition Examination Survey (NHANES III). Journal of Clinical Endocrinology and Metabolism 200287 489-499. (doi:10.1210/jcem.87.2.8182)

7 Kratzsch J, Fiedler GM, Leichtle A, Brugel M, Buchbinder S, Otto L, Sabri O, Matthes G \& Thiery J. New reference intervals for thyrotropin and thyroid hormones based on National Academy of Clinical Biochemistry criteria and regular ultrasonography of the thyroid. Clinical Chemistry 200551 1480-1486. (doi:10.1373/clinchem.2004. 047399)

8 Li C, Guan H, Teng X, Lai Y, Chen Y, Yu J, Li N, Wang B, Jiang F, Wang J et al. An epidemiological study of the serum thyrotropin reference range and factors that influence serum thyrotropin levels in iodine sufficient areas of China. Endocrine Journal 201158 995-1002. (doi:10.1507/endocri.K11E-101)

9 Schalin-Jantti C, Tanner P, Valimaki MJ \& Hamalainen E. Serum TSH reference interval in healthy Finnish adults using the Abbott Architect 2000i Analyzer. Scandinavian Journal of Clinical and Laboratory Investigation 201171 344-349. (doi:10.3109/00365513.2011.568630)

10 Sriphrapradang C, Pavarangkoon S, Jongjaroenprasert W, Chailurkit LO, Ongphiphadhanakul B \& Aekplakorn W. Reference ranges of serum TSH, FT4 and thyroid autoantibodies in the Thai population: the national health examination survey. Clinical Endocrinology 201480 751-756. (doi:10.1111/cen.12371)

11 Vadiveloo T, Donnan PT, Murphy MJ \& Leese GP. Age- and genderspecific TSH reference intervals in people with no obvious thyroid disease in Tayside, Scotland: the Thyroid Epidemiology, Audit, and Research Study (TEARS). Journal of Clinical Endocrinology and Metabolism 201398 1147-1153. (doi:10.1210/jc.2012-3191)

12 Volzke H, Alte D, Kohlmann T, Ludemann J, Nauck M, John U \& Meng W. Reference intervals of serum thyroid function tests in a previously iodine-deficient area. Thyroid 200515 279-285. (doi:10.1089/thy.2005.15.279)

13 Yoshihara A, Noh JY, Ohye H, Sato S, Sekiya K, Kosuga Y, Suzuki M, Matsumoto M, Kunii Y, Watanabe $\mathrm{N}$ et al. Reference limits for serum thyrotropin in a Japanese population. Endocrine Journal $20115 \mathbf{8 8}$ 585-588. (doi:10.1507/endocrj.K11E-082)

14 Arzideh F, Wosniok W \& Haeckel R. Indirect reference intervals of plasma and serum thyrotropin (TSH) concentrations from intralaboratory data bases from several German and Italian medical centres. Clinical Chemistry and Laboratory Medicine 201149 659-664. (doi:10.1515/CCLM.2011.114)

15 Laurberg P, Pedersen KM, Hreidarsson A, Sigfusson N, Iversen E \& Knudsen PR. Iodine intake and the pattern of thyroid disorders: a comparative epidemiological study of thyroid abnormalities in the elderly in Iceland and in Jutland, Denmark. Journal of Clinical Endocrinology and Metabolism 199883 765-769. (doi:10.1210/jcem. 83.3.4624)

16 Völzke H \& Ittermann T. TSH reference intervals: impact of iodine supply and clinical relevance. Nuklearmedizin 201335 238-240.

17 Zimmermann MB \& Andersson M. Update on iodine status worldwide. Current Opinion in Endocrinology, Diabetes, and Obesity 201219 382-387. (doi:10.1097/MED.0b013e328357271a)

18 Thamm M, Ellert U, Thierfelder W, Liesenkotter KP \& Volzke H. Iodine intake in Germany. Results of iodine monitoring in the German Health Interview and Examination Survey for Children and Adolescents (KiGGS). Bundesgesundheitsblatt, Gesundheitsforschung, Gesundheitsschutz 200750 744-749. (doi:10.1007/s00103-007-0236-4)

19 Ittermann T, Nautsch A, Schmidt CO, Kramer A, Below H, Remer T, Gartner R, Wallaschofski H \& Volzke H. High (but not low) urinary iodine excretion is predicted by iodine excretion levels from five years ago. Annals of Nutrition \& Metabolism 201158 335-342. (doi:10.1159/ 000331991)

20 Meng W \& Scriba P. Jodversorgung in Deutschland, Probleme und erforderliche Maßnahmen: update 2002 [Iodine supply in Germany, problems and required measures: update 2002]. Deutsches Ärzteblatt International 200299 A2560-A2564.

21 Volzke H, Alte D, Schmidt CO, Radke D, Lorbeer R, Friedrich N, Aumann N, Lau K, Piontek M, Born G et al. Cohort profile: the study of health in Pomerania. International Journal of Epidemiology 201140 294-307. (doi:10.1093/ije/dyp394)

22 Krohn K, Wohlgemuth S, Gerber H \& Paschke R. Hot microscopic areas of iodine-deficient euthyroid goitres contain constitutively activating TSH receptor mutations. Journal of Pathology 2000192 37-42. (doi:10. 1002/1096-9896(2000)9999:9999<::AID-PATH650 > 3.0.CO;2-3)

23 Meisinger C, Ittermann T, Wallaschofski $\mathrm{H}$, Heier M, Below $\mathrm{H}$, Kramer A, Doring A, Nauck M \& Volzke H. Geographic variations in the frequency of thyroid disorders and thyroid peroxidase antibodies in persons without former thyroid disease within Germany. European Journal of Endocrinology 2012167 363-371. (doi:10.1530/EJE-12-0111)

24 Volzke H, Ittermann T, Albers M, Friedrich N, Nauck M, Below H \& Kramer A. Five-year change in morphological and functional alterations of the thyroid gland: the study of health in Pomerania. Thyroid 201222 737-746. (doi:10.1089/thy.2011.0525)

25 Ziegler R \& Schwabe U. Schilddrüsentherapeutika. In Arzneiverordnungsreport 2013, pp 877-886. Eds U Schwabe \& D Paffrath, Heidelberg: Springer, 2013.

26 Lorenz-Wawschinek O, Tiran B, Eber O \& Langsteger W. Photometric determination of iodine in urine. Experimental and Clinical Endocrinology 1994102 57-58.

27 Gutekunst R, Becker W, Hehrmann H, Olbricht W \& Pfannenstiel P. Ultrasonic diagnosis of the thyroid gland. Deutsche Medizinische Wochenschrift 1988113 1109-1112. (doi:10.1055/s-2008-1067777)

28 CLSI. Defining, Establishing, and Verifying Reference Intervals in the Clinical Laboratory; Approved Guideline. 3rd edn. CLSI document C28-A3 2008.

29 Koenker R. Quantile Regression. New York, NY: Cambridge University Press, 2005.

30 Royston P, Sauerbrei W. Multivariable Model - Building: A Pragmatic Approach to Regression Anaylsis based on Fractional Polynomials for Modelling Continuous Variables. John Wiley \& Sons, 2008. 
31 Asvold BO, Bjoro T \& Vatten LJ. Association of serum TSH with high body mass differs between smokers and never-smokers. Journal of Clinical Endocrinology and Metabolism 200994 5023-5027. (doi:10.1210/ jc.2009-1180)

32 Ittermann T, Thamm M, Schipf S, John U, Rettig R \& Volzke H. Relationship of smoking and/or passive exposure to tobacco smoke on the association between serum thyrotropin and body mass index in large groups of adolescents and children. Thyroid 201323 262-268. (doi:10.1089/thy.2012.0110)

33 Knudsen N, Laurberg P, Rasmussen LB, Bulow I, Perrild H, Ovesen L \& Jorgensen T. Small differences in thyroid function may be important for body mass index and the occurrence of obesity in the population. Journal of Clinical Endocrinology and Metabolism 200590 4019-4024. (doi:10.1210/jc.2004-2225)

34 Volzke H, Schmidt CO, John U, Wallaschofski H, Dorr M \& Nauck M. Reference levels for serum thyroid function tests of diagnostic and prognostic significance. Hormone and Metabolic Research 201042 809-814. (doi:10.1055/s-0030-1263121)

35 Burkhardt K, Ittermann T, Heier M, Kirchberger I, Volzke H, Wallaschofski H, Below H, Nauck M \& Meisinger C. TSH-reference range of adults: results from the population-based study KORA F4.
Deutsche Medizinische Wochenschrift 2014139 317-322. (doi:10.1055/ s-0033-1360046)

36 Boucai L, Hollowell JG \& Surks MI. An approach for development of age-, gender-, and ethnicity-specific thyrotropin reference limits. Thyroid 201121 5-11. (doi:10.1089/thy.2010.0092)

37 Völzke H, Lüdemann J, Robinson DM, Spieker KW, Schwahn C, Kramer A, John U \& Meng W. The prevalence of undiagnosed thyroid disorders in a previously iodine-deficient area. Thyroid $2003 \mathbf{1 3}$ 803-810. (doi:10.1089/105072503768499680)

38 Pedersen OM, Aardal NP, Larssen TB, Varhaug JE, Myking O \& Vik-Mo $\mathrm{H}$. The value of ultrasonography in predicting autoimmune thyroid disease. Thyroid 200010 251-259. (doi:10.1089/ thy.2000.10.251)

39 Rago T, Chiovato L, Grasso L, Pinchera A \& Vitti P. Thyroid ultrasonography as a tool for detecting thyroid autoimmune diseases and predicting thyroid dsfunction in apparently healthy subjects. Journal of Endocrinological Investigation 200124 763-769. (doi:10.1007/ BF03343925)

40 Caron PJ, Nieman LK, Rose SR \& Nisula BC. Deficient nocturnal surge of thyrotropin in central hypothyroidism. Journal of Clinical Endocrinology and Metabolism 198662 960-964. (doi:10.1210/jcem-62-5-960)

Received 20 October 2014

Revised version received 19 November 2014

Accepted 1 December 2014 